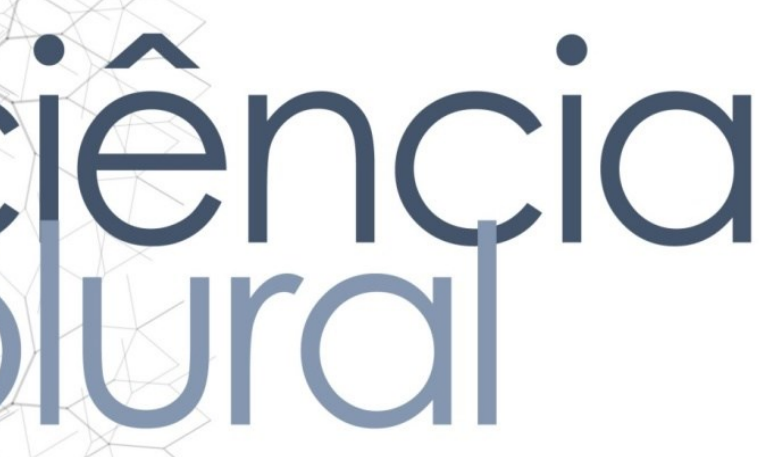

\title{
A BRINQUEDOTECA NA ASSISTÊNCIA A CRIANÇAS COM CÂNCER: A VISÃO DOS FAMILIARES
}

\section{The toys for assisting children with cancer: the vision of the familiars}

Leiliandry de Araújo Melo • Enfermeira pela Universidade Estadual de Ciências da Saúde de Alagoas. Mestranda em Ciências da Saúde na Universidade de Pernambuco. E-mail: leiliandrymelo@hotmail.com

Leylane de Araújo Melo • Enfermeira pela Universidade Estadual de Ciências da Saúde de Alagoas. Especialista em UTI pela CBPEX. E-mail: leylanemelo@hotmail.com

Ana Marlusia Alves Bomfim • Odontóloga, Doutoranda em Ensino da Saúde pela Universidade Federal de São Paulo. E-mail: anamarlusia@yahoo.com.br

Andréa Marques Vanderlei Ferreira - Doutora em química e Biotecnologia pela Universidade Federal de Alagoas. E-mail: deadoutorado@hotmail.com

Luciana da Conceição Silva • Enfermeira pela Universidade Estadual de Ciências da Saúde de Alagoas. E-mail: luciana.silvasma@gmail.com

Morgana Valesca de Melo Bezerra - Enfermeira pela Universidade Estadual de Ciências da Saúde de Alagoas. E-mail: morgana.valesca@hotmail.com

Autor responsável pela correspondência:

Leiliandry de Araújo Melo. E-mail: leiliandrymelo@hotmail.com 


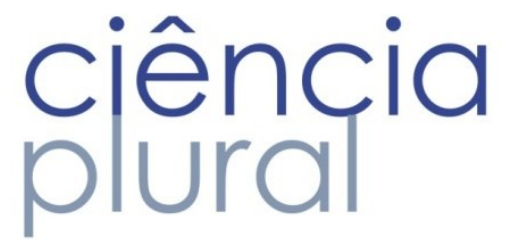

RESUMO

Objetivo: Verificar a visão dos familiares sobre o uso da brinquedoteca como recurso terapêutico na assistência à criança com câncer. Métodos: Trata-se de um estudo transversal que utilizou uma amostra de conveniência. Foi aplicado um formulário específico, contendo questões direcionadas a conhecer 0 perfil sóciodemográfico dos acompanhantes (27 familiares que acompanhavam as crianças com câncer), dados pessoais da criança e sua relação com a brinquedoteca, além de questões direcionadas aos acompanhantes após observação da criança na brinquedoteca, as quais foram elaboradas considerando três escores de respostas. Resultados: Os familiares responderam que a brinquedoteca propicia uma melhor qualidade de vida para as crianças, na medida em que diminui o estresse e contribui para a melhoria do seu bem estar. Além disso, facilita a compreensão da condição que vivem, minimizando as dificuldades de aceitação do tratamento e melhorando o relacionamento com outras crianças e com os profissionais. Conclusão: Os resultados nos permite concluir que a brinquedoteca possibilita a continuidade do desenvolvimento cognitivo da criança, favorecendo as suas potencialidades, ajudando-as a compreender sua condição, melhorando a adesão ao tratamento, sua sociabilidade, minimizando 0 sofrimento e humanizando o processo de cura e recuperação.

Palavras-Chave: Jogos e brinquedos; Criança; Câncer; Humanização do tratamento.

\section{ABSTRACT}

Objective: To verify the family members' view on the use of the toy library as a therapeutic resource in the care of children with cancer. Methods: This was a cross-sectional study using a convenience sample. A specific form was applied, containing questions considering three response scores and aimed at knowing the socio-demographic profile of the companions ( 27 family members who accompanied the children with cancer), the child's personal data and their relationship with the toy library, besides issues addressed to the companions After watching the child in the toy library. Results: $59.3 \%$ of family members answered that the toy library has a very relevant socializing role, helping in the relationship with other children and professionals. $55.6 \%$ of family members also stated that there was a change in the perception of the child in the face of his illness and for the majority of respondents (85.2\%), the toy library helped to improve the child's well-being and reduce stress. Conclusion: The results allow us to conclude that the toy library allows the continuity of the child's cognitive development, favoring their potentialities, helping them understand their condition, improving adherence to treatment, sociability, minimizing suffering and humanizing the healing process and recovery.

Keywords: Games and toys; Child; Cancer; Quality of life. 


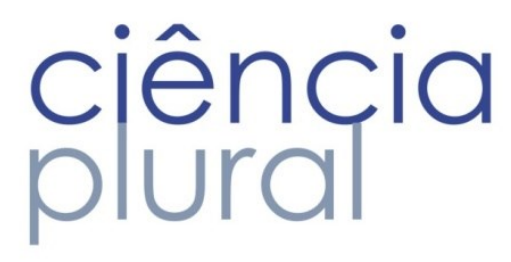

\section{Introdução}

O câncer infantil é uma doença que requer múltiplas admissões hospitalares e diversas modalidades terapêuticas. Neste processo as crianças acabam sendo forçadas a deixar suas casas e o convívio social para se adaptar ao ambiente hospitalar e tudo o que envolve ${ }^{1}$.

A doença e hospitalização das crianças representa uma ruptura em suas vidas cotidianas: precisam se afastar das atividades escolares, dos seus brinquedos, da sua casa e do convívio com seus colegas. Passam a se encontrar em um local restrito, onde rotinas hospitalares e do próprio ambiente reduzem 0 leque de atividades que podem atrapalhar o seu desenvolvimento natural. A hospitalização é percebida como uma agressão contra o mundo de uma criança, expondo a mesma a dor e ao sofrimento, podendo até interferir na sua vontade e capacidade de brincar².

Acredita-se que o enfrentamento das repercussões psicológicas da doença é favorecido com a utilização do lúdico, principalmente com a abordagem em grupo, integrando as crianças e seus familiares para proporcionar momentos de satisfação e de reorganização das experiências. A criança hospitalizada com câncer necessita de uma equipe multiprofissional e de um espaço para expressar suas emoções, visando compreender a sua vivência por meio das atividades lúdicas que auxiliem a promoção da saúde integral. Nesse contexto, a utilização do brincar no hospital promove uma ação terapêutica e auxilia na atenção integral às necessidades da criança ${ }^{3}$.

Durante o brincar aparecem elementos bastante singulares de cada pessoa, as capacidades criativas, os limites e as preferências. Por meio do brincar a criança descobre o mundo que a cerca, aprende a se comunicar e explorar objetos, experimenta a possiblidade de criar, recriar, fracassar, mas também de encontrar a solução de problemas ${ }^{4}$. O brincar é terapêutico, é um meio seguro de expressão verbal e não verbal das emoções, preocupações e percepções em relação à experiência vivenciada. $A$ possiblidade de brincar com outras crianças ameniza o sofrimento e desvia a atenção da situação hospitalar, acelerando o processo de recuperação da criança 5 .

Reconhece-se, portanto, que o brincar é um elemento fundamental na vida de qualquer criança e é capaz de reequilibrá-la, reciclando suas emoções, desenvolvendo atenção e concentração ${ }^{6} .0$ ambiente hospitalar pode representar um espaço para a criança encontrar o seu mundo natural por meio das atividades lúdicas. Mesmo diante das mudanças provocadas pelo surgimento de uma doença, o ambiente 
hospitalar pode proporcionar espaços destinados para o brincar, representando a valorização da vida e a ampliação da noção de saúde física e psíquica³ .

Nesse sentido, buscando oferecer um ambiente que permitisse a continuação do ciclo criativo das crianças doentes, surgiram as brinquedotecas hospitalares. São espaços que visam promover 0 ambiente hospitalar como local mais humanizado e que priorize não só a questão orgânica do adoecimento, mas que também entenda a criança como um ser biopsicossocial e ocupacional e que pode estar fragilizado emocionalmente. A brinquedoteca explora a ludicidade das crianças, estimulando-as a brincar, criar, aprender e viver situações que tornam 0 ambiente bastante acolhedor e as aproximam de elementos que constituem o universo infantil 4 .

As atividades lúdicas amenizam a experiência estressante da hospitalização, transformam os sentimentos e procedimentos negativos que deverão ser superados pela criança e sua família. A participação familiar, inclusive, é mais um elemento que alicerça o desempenho e tratamento tranquilo da criança exposta ao câncer e cria um ambiente de confiança. A família é fundamental para a adaptação da criança ao ambiente hospitalar, porque traz segurança e colabora para o enfrentamento das adversidades, promovendo melhor aceitação da sua condição e do tratamento ${ }^{5}$.

Diante destes aspectos, o objetivo deste estudo foi verificar a visão dos familiares sobre o uso da brinquedoteca como recurso terapêutico na assistência à criança com câncer.

\section{Método}

\section{Desenho do estudo}

O estudo foi do tipo transversal, conduzido na Associação de Pais e Amigos Leucêmicos de Alagoas (APALA). A amostra foi de conveniência composta por familiares que acompanhavam as crianças na brinquedoteca nos meses de junho e julho de 2013. Foram realizadas entrevistas com 27 familiares entre mães, pais, avós e tia. As entrevistas consistiam da aplicação de um formulário específico (Apêndice 1) dividido em três partes: (1) caracterização sociodemográfica seus familiares, (2) dados pessoais da criança e sua doença e (3) opinião dos familiares em relação à mudanças no comportamento da criança com câncer com outras crianças e com os profissionais de saúde. Perguntou-se também se houve melhora na qualidade do tratamento, na reação diante da doença, do tratamento e do seu bem-estar e se houve diminuição do estresse físico e mental. 


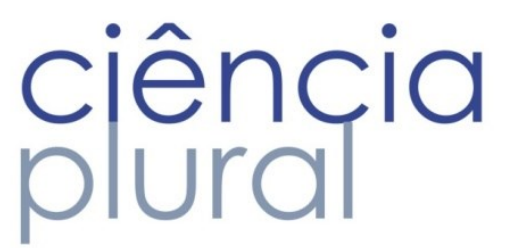

Enquanto as crianças estavam na brinquedoteca e após uma explicação dos objetivos da pesquisa e do conteúdo das questões, os familiares foram convidados a participar voluntariamente do estudo. Os acompanhantes que aceitaram participar receberam um Termo de Consentimento Livre e Esclarecido e, após o esclarecimento das dúvidas, iniciava-se a aplicação do formulário. Para cada um dos familiares era realizada a leitura das perguntas e alternativas de respostas, sendo estas agrupadas em escores correspondentes a "pouca ou nenhuma", "média" ou "muita". O familiar então escolhia a opção que mais se aproximava da sua opinião. Quando necessário, fazia-se a leitura novamente a fim de não ficar nenhuma dúvida. Cada entrevista durou cerca de 10 a 15 minutos.

O projeto foi aprovado pelo Comitê de Ética em Pesquisa da Universidade Estadual de Ciências da Saúde de Alagoas pelo Protocolo $n^{0} 1815$. Os dados foram armazenados no programa Microsoft Excel ano 2010 e analisados no software estatístico EPI-INFO 6.0. Após análise dos formulários, realizou-se um levantamendo de todas as respostas de modo a agrupá-las e verificar as frequências absoluta e relativa para as variáveis categóricas. As variáveis quantitativas que tiveram distribuição normal foram apresentadas por média e desvio padrão, enquanto que as sem distribuição normal foram representadas por mediana e percentis (P25; P75).

\section{Resultados}

Os 27 familiares das crianças em tratamento eram em sua maioria do sexo feminino $(92,6 \%)$. Foram representados pelas mães $(70,3 \%)$, seguindo das avós $(18,5 \%)$, pais $(7,5 \%)$ e tia $(3,7 \%)$. Todos se encontravam em mais de um turno com a criança, seja quando estavam na APALA ou mesmo quando retornavam as suas casas. A maior parte dos familiares possuía Ensino Fundamental Incompleto e eram do lar. Outros dados são apresentados na Tabela 1.

A média de idade das crianças foi de sete anos. Do sexo feminino se obteve uma amostra de 66,7 $\%$ e do sexo masculino $33,3 \%$. A quantidade de dias da semana que a criança frequentava a brinquedoteca estava proporcional à duração da visita. Ou seja, se uma paciente e seu familiar vinham passar três dias na APALA, durante esses mesmos três dias a criança visitava pelo menos em um turno a brinquedoteca.

Sobre o tempo de uso da brinquedoteca e a duração do tratamento e acompanhamento pela APALA, às estatísticas corresponderam aos mesmos números, indicando que desde o diagnóstico e inserção do tratamento, as crianças já estão sendo acompanhadas pela casa de apoio e usufruindo das atividades 


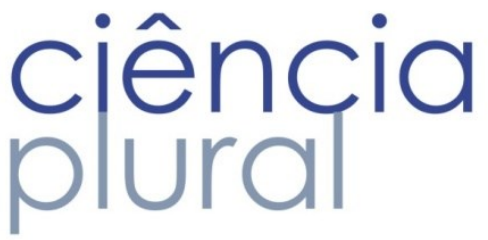

lúdicas: $25,9 \%$ dos familiares revelaram que suas crianças frequentavam a brinquedoteca num período de 1 a 6 meses; 22,2 \% entre 6 a 12 meses; 25,9\% entre 1 a 2 anos e 25,9\% há mais de 2 anos.

Tabela 1: Dados sociodemográficos dos familiares das crianças com câncer, Maceió/AL, 2013.

\begin{tabular}{llc}
\hline \multicolumn{1}{c}{ VARIÁVEIS } & $\mathrm{n}$ & $\%$ \\
\hline ESCOLARIDADE & & \\
\hline Analfabeto & 04 & 14,8 \\
Ensino Fundamental Incompleto & 09 & 33,3 \\
\hline Ensino Fundamental Completo & 02 & 7,40 \\
\hline Ensino Médio Incompleto & 05 & 18,5 \\
\hline Ensino Médio Completo & 06 & 22,2 \\
Ensino Superior Incompleto & 01 & 3,70 \\
\hline TIPO DE OCUPAÇÃO & & \\
\hline Dona de casa & 22 & 81,5 \\
\hline Pescadora & 01 & 3,70 \\
\hline Cortador de cana & 01 & 3,70 \\
\hline Autônomo & 03 & 11,1 \\
\hline
\end{tabular}

Os familiares revelaram que a relação da criança com as outras crianças mudou muito após as atividades na brinquedoteca, bem como afirmaram que a aproximação dos profissionais para realização dos procedimentos ficou mais fácil, o que confirmou o papel socializador da brinquedoteca (Gráfico 1). 


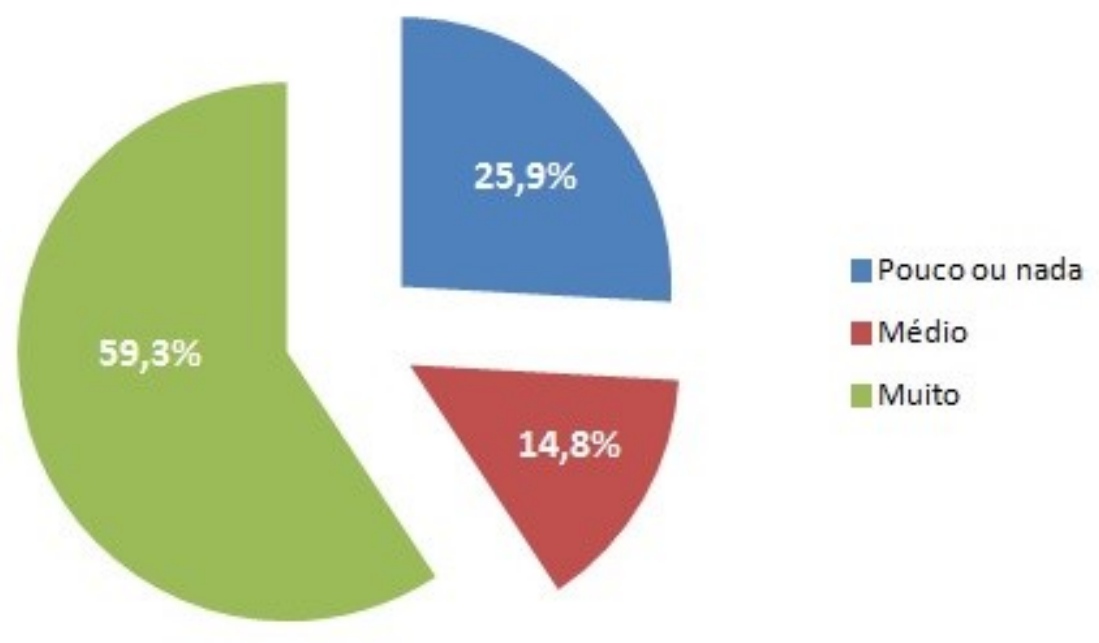

Gráfico 1: Papel socializador da brinquedoteca sob a visão dos familiares das crianças com câncer, Maceió/AL, 2013.

Segundo os familiares, depois de começarem a frequentar a brinquedoteca, as crianças passaram a reagir muito melhor diante da doença e do tratamento de quimioterapia e radioterapia, o que influenciou muito na qualidade da terapêutica. Portanto, o uso dos recursos lúdicos mudou muito a percepção do que é o câncer para as crianças (Gráfico 2).

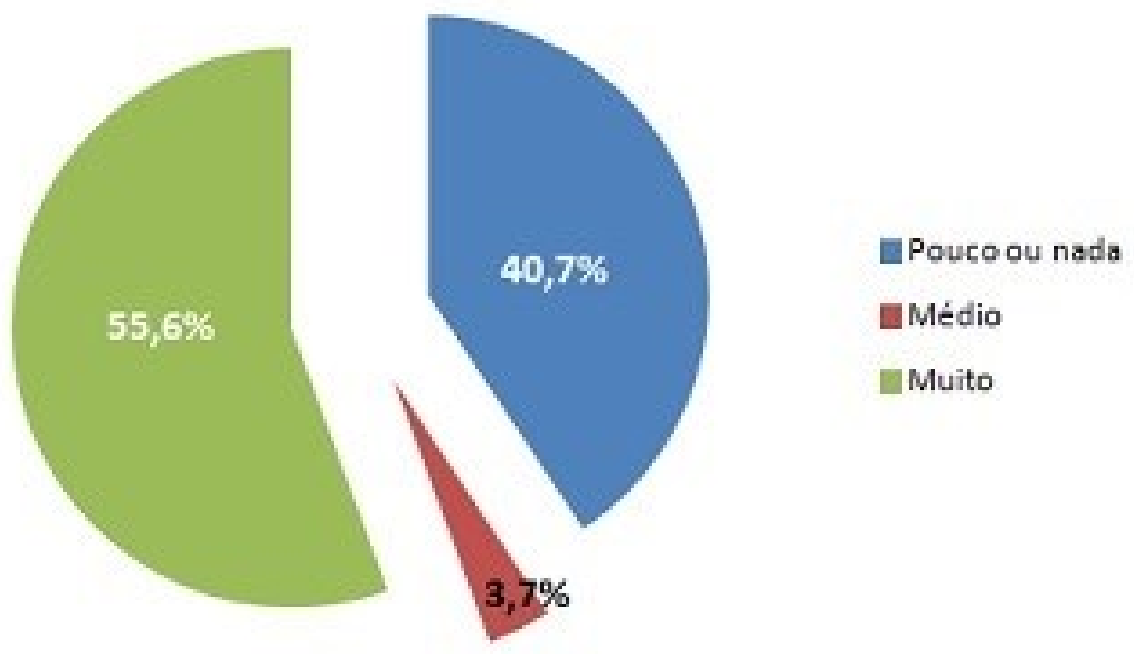

Gráfico 2: Mudança na percepção do que é câncer para as crianças após a participação nas atividades da brinquedoteca, Maceió, 2013. 


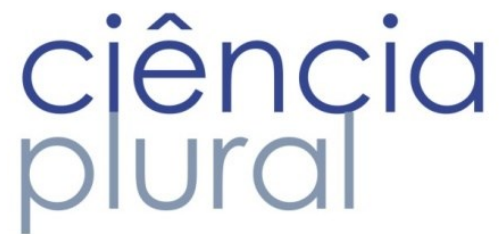

Além de ajudar no comportamento socializador da criança e na sua compreensão sobre a doença, a brinquedoteca ajudou a diminuir o estresse e melhorou o bem estar de forma geral das crianças (Tabela 2).

Tabela 2: Melhora da qualidade de vida das crianças de acordo com a visão dos familiares após o uso da brinquedoteca, Maceió, 2013.

\begin{tabular}{|c|c|c|c|c|c|c|}
\hline \multirow[t]{2}{*}{$\begin{array}{l}\text { Opinião sobre a } \\
\text { influência da } \\
\text { atividade lúdica }\end{array}$} & \multicolumn{2}{|c|}{$\begin{array}{c}\text { POUCA } \\
\text { OU NENHUMA }\end{array}$} & \multicolumn{2}{|c|}{ MÉDIA } & \multicolumn{2}{|c|}{ MUITA } \\
\hline & $\mathrm{n}$ & $\%$ & n & $\%$ & $\mathrm{n}$ & $\%$ \\
\hline Diminuem o estresse & 02 & 7,40 & 02 & 7,40 & 23 & 85,2 \\
\hline $\begin{array}{l}\text { Melhoram o bem } \\
\text { estar }\end{array}$ & 01 & 3,70 & 03 & 11,1 & 23 & 85,2 \\
\hline
\end{tabular}

Para que todos esses benefícios expostos pelos familiares sejam proporcionados e sentidos pelas crianças, é imprescindível uma assistência humanizada por parte dos responsáveis pela brinquedoteca. Segundo os entrevistados, 40,7 \% considera boa a assistência prestada pelos voluntários e 59,3\% considera uma assistência ótima.

A condição de saúde de uma criança com câncer requer cuidados e um olhar humanizado para assistência. Ficou claro os benefícios do recurso lúdico no tratamento e isso exige uma reflexão dos gestores e profissionais de saúde no sentido de buscar alternativas para os problemas detectados.

\section{Discussão}

Os benefícios da brinquedoteca ficou evidente após as entrevistas com os familiares. As crianças ficaram mais sociáveis e menos resistentes aos procedimentos do tratamento, porque a brinquedoteca mudou suas visões sobre a doença e melhorou a qualidade de vida.

O desenvolvimento de atividades lúdicas representa uma possibilidade por meio da qual os efeitos do processo de hospitalização são minimizados e as crianças fortalecem vínculos, expressam sentimentos e se reestruturam mediante as experiências traumáticas ${ }^{3}$. 0 lúdico é uma ferramenta capaz de tornar 0 processo de cuidar menos traumático ${ }^{7}$. Essas atividades, de acordo com algumas crianças entrevistadas em um estudo, proporcionam alegria e diversão e promovem a socialização com outras pessoas. São consideradas essenciais em seus tratamentos, pois aumentam o bem-estar e reduzem o desconforto da 


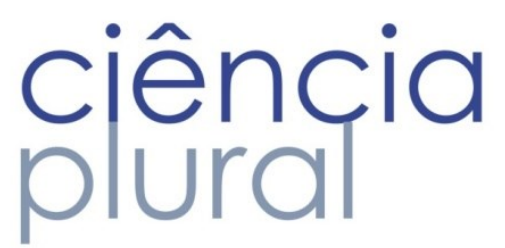

hospitalização ${ }^{1}$. Assim, tanto o papel socializador, quanto a melhora na qualidade de vida através do bem estar vão de encontro aos resultados do nosso estudo.

Lemos et al. ${ }^{9}$ verificaram a impressão das mães sobre o uso da brinquedoteca e revelaram que as crianças permitiam mais facilmente os procedimentos e ficavam menos reticentes aos profissionais após saberem que iam para brinquedoteca. A promessa das atividades lúdicas encorajavam as crianças ${ }^{9}$. Isso está de acordo com o papel socializador da brinquedoteca encontrado pelo nosso trabalho e refletido pela facilidade também de aproximação dos profissionais, o que foi reiterado por outras pesquisas 9,10 .

Nesse sentido, o brincar não é uma atividade que deve ser permitida a criança caso haja "sobra" de tempo ou pessoas com vontade de cuidar, mas o brincar deve fazer parte da assistência para que a criança cresça e se desenvolva tendo suas necessidades atendidas ${ }^{7}$. O hospital e a brinquedoteca assumem, então, um lugar de destaque no resgate do prazer de brincar e do desenvolvimento infantil. Para as crianças com câncer, nesses ambientes devem ser desenvolvidas brincadeiras para promover alegria, aprendizado e interação social, assumindo posição contrária à dor e estresse causados pelo tratamento².

A brinquedoteca vem enriquecer o relacionamento entre a criança e seus familiares, bem como com outras crianças, promovendo a interação grupal. Um estudo verificou que $97,8 \%$ dos familiares referiu melhora no estado emocional da criança ao participar das atividades oferecidas ${ }^{5}$. Entende-se que diminuir o estresse e melhorar o bem estar influenciam de maneira geral no estado emocional da criança e isso pode também ser verificado no nosso estudo através dessas variáveis.

Outro estudo 2 afirma que crianças que não brincavam desde 0 início do tratamento, após frequentarem a brinquedoteca foram incentivadas a retomar as atividades lúdicas. Outro aspecto revelado no estudo é que o brincar é um meio de promoção de cuidados holísticos e quando a criança interage com outras na mesma condição de adoecimento acaba redescobrindo o prazer de viver ${ }^{2}$.

A oportunidade que as crianças têm de conviver com outras em um espaço lúdico como as brinquedotecas favorece a compreensão de sua condição, a expressão de suas emoções e auxiliam na promoção integral da saúde ${ }^{3}$. Nosso estudo mostrou exatamente isso: para os familiares as crianças mudaram sua compreensão da doença e passaram a reagir melhor diante do tratamento. $O$ brincar se torna terapêutico, capaz de promover a continuidade do tratamento em virtude da criança compreendê-lo melhor $^{8}$, amenizando as repercussões do adoecimento na esfera psíquica e física ${ }^{3}$. A brinquedoteca se mostra, então, como uma saída para a criança se reinventar e buscar formas de se adaptar melhor ao 


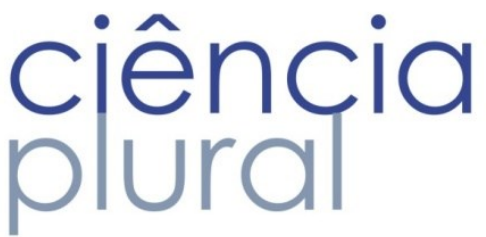

novo cenário em que está inserida, tornando-se mais calma, se não feliz, porém com menos tristeza e maior aceitação ao cuidado que lhe é prestado?.

A melhora na qualidade de vida da criança e também da sua família foi destacado em um estudo que verificou os efeitos positivos dos projetos lúdicos quando a criança entra no mundo do faz de conta e se alimenta do prazer de brincar ${ }^{5}$. Segundo profissionais entrevistados em outro estudo, ao inserir o lúdico na rotina do cuidado, as crianças mudaram de humor, estavam sempre sorrindo ${ }^{7} \mathrm{e}$ isso pode ser traduzido como diminuição do estresse encontrado no nosso estudo. Além disso, ficou evidente a satisfação e a alegria das crianças após frequentarem a brinquedoteca ${ }^{7}$. Estes resultados refletem exatamente na melhora do bem estar das crianças e reitera ou confirma aqueles encontrados na presente pesquisa.

Contudo, todas essas facetas do brincar tem que ser acompanhadas por adultos que possam observar o comportamento da criança frente ao uso da brinquedoteca. Os pais ou acompanhantes são essencialmente importantes, pois conduzem a avaliação da assistência prestada neste ambiente sugerindo medidas quando necessário para aprimorar a qualidade do atendimento ${ }^{10-11}$. Além disso, a maneira como o familiar lida com o estado de saúde da criança reflete na aceitação e recuperação desta. A criança entende o que está ocorrendo, ao contrário do que muitos pensam, então a reação agradável do familiar é fundamental para que a criança sinta confiança e tenha uma recuperação efetiva?

O cuidado lúdico tem se mostrado como uma estratégia no cuidado para com as crianças que vivenciam um processo de adoecimento. Brincar potencializa o bem estar da criança e da família quando diminui o clima de tensão e medo que se abate diante de um mau diagnóstico. Para tanto, é necessário que a família se alie à equipe de saúde e esteja aberta ao diálogo para encontrar caminhos de atenuar as dificuldades rotineiras da hospitalização e facilitar a aceitação e recuperação da criança ${ }^{7}$

O brincar na infância é um direito fundamental previsto no Estatuto da Criança e do Adolescente e precisa tomar lugar central no processo de cuidar à crianças doentes. A redescoberta do prazer de brincar proporciona benefícios para o desenvolvimento biopsicossocial da criança e também para os familiares, que passam a se sentir estimulados a lutar contra o câncer quando percebem a criança reagindo e brincando? 


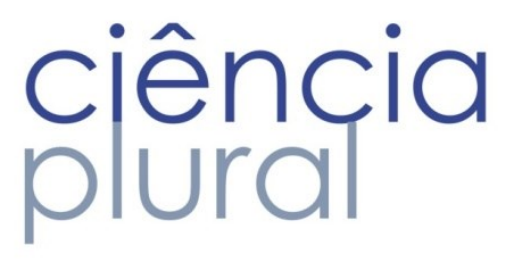

Conclusão

A brinquedoteca proporciona melhoras significativas na assistência a crianças com câncer em tratamento ambulatorial e hospitalar, o que fica evidente principalmente para as pessoas que estão acompanhando. Sendo assim, os recursos amplos e diferentes que a brinquedoteca dispõe contribuem para redução do sofrimento das crianças ao passo que diminuem o estresse e melhoram seu bem estar. Além disso, há destaque para o perfil socializador da brinquedoteca quando se observam mudanças no relacionamento com as outras crianças e com os profissionais. Ocorre, finalmente, quebra de barreiras durante o tratamento quando a criança muda seu percepção de doença após frequentar o ambiente lúdico, o que humaniza o tratamento e torna menos sofrido o processo de recuperação.

\section{Agradecimentos}

Os autores agradecem a Fundação de Amparo à Pesquisa do Estado de Alagoas (FAPEAL) pela bolsa de iniciação científica de um dos autores quando do desenvolvimento da pesquisa.

\section{Referências}

1. Lima KYN de, Santos VEP. O lúdico como estratégia no cuidado à criança com câncer. Rev gaúcha Enferm. 2015; 36(2):76-81.

2. Silva LF, Cabral IE. O resgate do prazer de brincar da criança com câncer no espaço hospitalar. Rev Bras Enferm. 2015; 68(3):391-7.

3. Azevedo AVS. O brincar da criança com câncer no hospital: análise da produção científica. Estud Psicol. 2011; 28(4):565-72.

4. Monteiro LS, Corrêa VAC. Reflexões sobre o brincar, a brinquedoteca e o processo de hospitalização. Rev Para Med. 2012; 26(3).

5. Moraes MCAF, Buffa MJMB, Motti TFG. As atividades expressivas e recreativas em crianças com fissura labiopalatina hospitalizadas: visão dos familiares. Rev Bras Educ Espec. 2009; 15(3):453-70. 6. Melo LL, Valle ERM. A Brinquedoteca como possibilidade para desvelar o cotidiano da criança em tratamento ambulatorial. Rev Esc Enferm USP. 2010; 44(2):517-25.

7. Marques EP, Garcia TMB, Anders JC, Luz JH da, Rocha PK, Souza S. Lúdico no cuidado à criança e ao adolescente com câncer: perspectivas da equipe de de enfermagem. Esc Anna Nery. 2016; 20(3):1-8. 


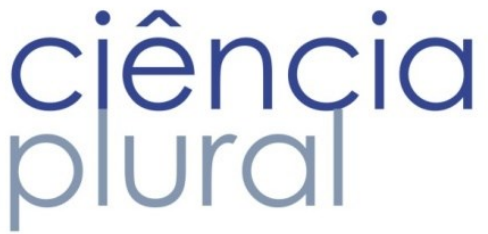

8. Nicola GDM, llha S, Dias MV, Freitas HMB, Backes DS, Gomes GC. Percepções do familiar cuidador acerca do cuidado lúdico à criança hospitalizada. Rev enferm UFPE online. 2014; 8(4):981-6.

9. Lemos L, Pereira W, Andrade J, Andrade A. Vamos cuidar com brinquedos? Rev Bras Enferm. 2010; 63(6):950-5.

10. Nascimento RR, Costa MAS, Madeira MZA, Julião MAS, Amorim FCM. A brinquedoteca como instrumento na assistência à criança hospitalizada, sob o olhar do cuidador. R. Interd. 2016; 9(2):29-37. 11. Giacomello KJ, Melo L de L. Do faz de conta à realidade: compreendendo o brincar de crianças institucionalizadas vítimas de violência por meio do brinquedo terapêutico. Cien Saude Colet. 2011; 16(Supl. 1):1571-80. 


\section{Apêndice 1}

FORMULÁRIO DA PESQUISA: A BRINQUEDOTECA NA ASSISTÊNCIA A CRIANÇAS COM CÂNCER:

A VISÃO DOS FAMILIARES

$\mathbf{N}^{\circ}$

\section{DADOS PESSOAIS DO ACOMPANHANTE}

$\begin{array}{llllll}\text { NOME: } & \text { SEXO: } & \square & F & \square\end{array}$

IDADE: $\quad$ PROFISSÃO:

ESCOLARIDADE:

1. Ensino fundamental completo

2. Ensino fundamental incompleto

3. Ensino médio completo

4. Ensino médio incompleto

5. Ensino superior completo

6. Ensino superior incompleto

7. Outro:

PARENTESCO COM A CRIANÇA:

EM QUE TURNO (S) O SR.(A) FICA COM A CRIANÇA: $\square \quad$ Manhã $\quad \square \quad$ Tarde $\quad \square \quad$ menos que um turno.

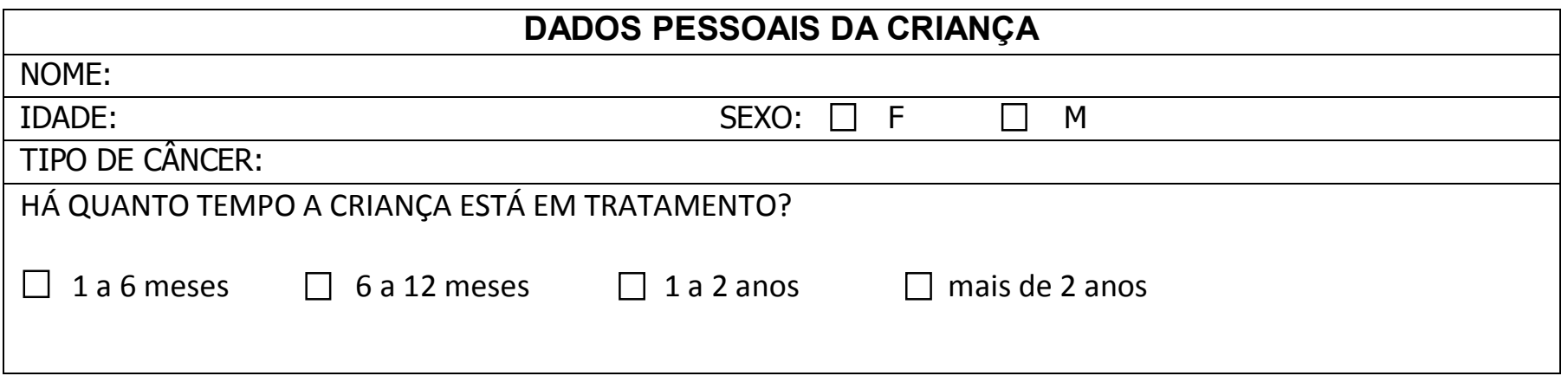




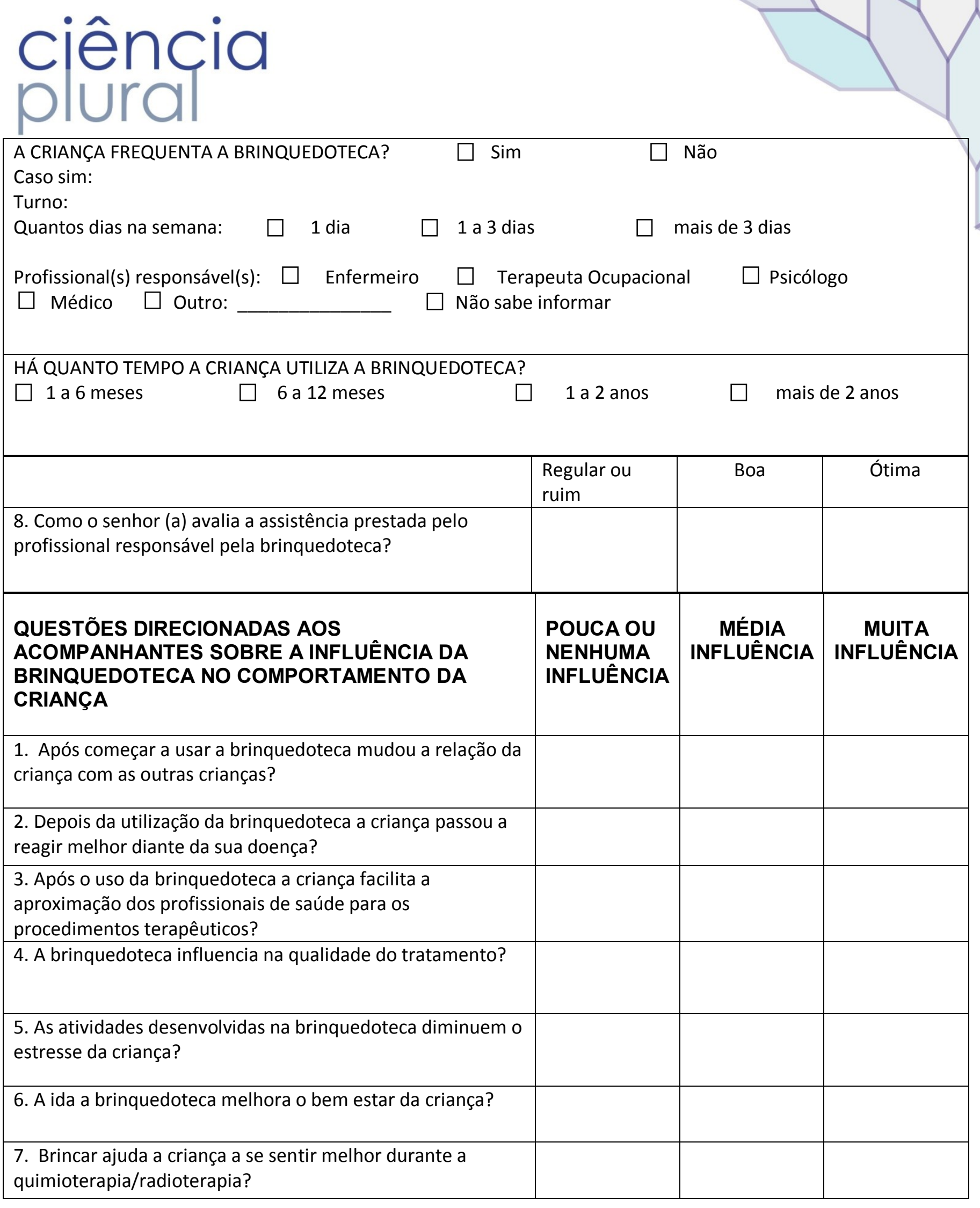

